\title{
Víctimas moriscas del corso turco-berberisco. Noticias y testimonios en los procesos criminales valencianos*
}

\author{
Jorge Antonio Catalá Sanz \\ Universitat de València
}

\section{Resumen}

El peligro cierto y recurrente de la cooperación de los moriscos con los corsarios turcos y berberiscos no autoriza, sin embargo, a considerar a la minoría morisca en su conjunto como una "quinta columna» siempre dispuesta a conspirar contra la Corona y a prestar ayuda a los enemigos de la otra orilla. Los procesos criminales que la Real Audiencia de Valencia sustanció contra corsarios e infiltrados ofrecen testimonios que no solo revelan la amplia diversidad de actitudes y respuestas de los nuevos convertidos ante las grandes fugas, los ataques a las poblaciones litorales y la captura de cristianos viejos, sino también que ellos mismos sufrieron los efectos de las incursiones de los moros de la mar: algunos porque no dudaron en hacerles frente para defender a sus vecinos cristianos, otros muchos porque fueron violentamente compelidos a marcharse a África a pesar de que deseaban permanecer en su tierra.

Palabras clave: moriscos, corso, quinta columna, diversidad, justicia penal, procesos criminales.

* Este trabajo se ha realizado en el marco del proyecto «Privilegio, trabajo y conflictividad. La sociedad moderna de los territorios hispánicos del Mediterráneo occidental entre el cambio y las resistencias», financiado por el Ministerio de Ciencia e Innovación (PGC20I8-094150-B-C2I). 


\section{Victimes morisques del cors turc-berber. Notícies $i$ testimonis als proces- sos criminals valencians}

\section{Resum}

Tot i que la cooperació dels moriscos amb els corsaris turcs i barbarescos fou un perill cert i recurrent, això no permet considerar la minoria morisca en conjunt com una "quinta columna» sempre disposada a conspirar contra la corona i a prestar ajuda als enemics de l'altra riba. Els processos criminals que la Real Audiència de València va substanciar contra corsaris i infiltrats ofereixen testimoniatges que no sols revelen la gran diversitat d'actituds i respostes dels nous convertits davant les grans fugides, els atacs a les poblacions litorals i la captura de cristians vells, sinó també que els mateixos moriscos van patir els efectes de les incursions dels moros de la mar: alguns perquè no van dubtar a fer-los front per a defensar els seus veïns cristians, molts altres perquè van haver de marxar a Àfrica violentament constrets, a pesar que desitjaven romandre a la seva terra.

Paraules clau: moriscos, cors, quinta columna, diversitat, justícia penal, processos criminals.

\section{Morisco victims of the Ottoman and Barbary corsairs. News and testi- monies in the Valencian criminal proceedings}

\section{Abstract}

The existing and constant threat of cooperation between the Moriscos and the Turkish and North African corsairs does not authorize, however, classification of this whole community as an Ottoman «Fifth Column» always ready to conspire against the Crown and to help their foreign enemies. The criminal proceedings conducted by the Real Audiencia («Royal Court») of Valencia against corsairs and alleged covert agents provide us with evidence of a broad range of New Converts' attitudes and responses towards massive emmigration schemes, attacks on coastal populations and abductions of Old Christians. Moreover, they reveal that Moriscos themselves were exposed to the impact of Muslim privateering: some of them because they had no hesitation in standing up to the corsairs and defending their Christian neighbours, many more as they were violently forced to leave to Africa although they wished to stay in their home country. 
Keywords: Moriscos, privateering, Fifth Column, diversity, penal justice, criminal proceedings.

En un trabajo recientemente publicado, Juan Francisco Pardo ha analizado con finura el peligro cierto que las fugas, los contactos con el norte de África y las conjuras de los moriscos valencianos representaban para la monarquía, así como la propensión de las autoridades — tanto las del reino como los oficiales del rey-, a exagerar el riesgo, sobre todo en las coyunturas más delicadas o si creían que lo aconsejaba el bien de la república, la razón de Estado o el servicio de Dios. Buen conocedor de las discrepancias que entre los historiadores ha suscitado la distancia, tan sensible a los cambios contextuales y por ello tan difícil de medir, entre el alcance real del peligro morisco y la percepción de este por parte de la Corona, de los poderes territoriales y de la población cristiano-vieja, el profesor Pardo ofrece una breve pero lúcida síntesis de las diferencias interpretativas en torno a este asunto; desde la firme convicción de la existencia de «inteligencias secretas» entre moriscos, berberiscos y turcos de Lafuente, Danvila o Boronat hasta el escepticismo de Márquez o La Parra, quienes rebajan o cuestionan la gravedad de dicha amenaza, pasando por una gama, más o menos amplia, de matices y cautelas en función de la etapa, ocasión o territorio que se analice y de las fuentes de que se dis-

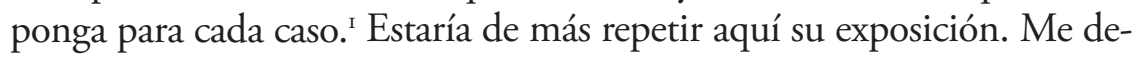
tendré solo en un punto que afecta al propósito de este estudio: la aplicación del concepto de «quinta columna» a la minoría morisca.

La idea de que los moriscos eran «enemigos domésticos» de los que la monarquía de Felipe II tenía motivos fundados para desconfiar, que ya encontramos formulada antes de la expulsión ${ }^{2}$ y a cuyo arraigo histo-

I. Juan Francisco Pardo Molero, «¿Emigrantes o conspiradores? Fugas, tramas y peligro morisco en el reino de Valencia (I525-1609)", en B. Vincent, coord., Comprender la expulsión de los moriscos en España (I609-I6I4), Universidad de Oviedo, Oviedo, 2020, pp. 193-226, en particular 193-196.

2. Bernard Vincent y Rafael Benítez SÁnchez-Blanco, «Estudio introductorio» a su edición de Jaime BLEDA, Corónica de los moros de España, Biblioteca Valen- 
riográfico contribuyó Braudel decisivamente, ${ }^{3}$ obtuvo el respaldo de Reglà tras la publicación del Mediterráneo ${ }^{4} \mathrm{y}$, ańos más tarde, siguiendo sus pasos, de Hess; 5 en el caso del primero a partir de las noticias halladas en los informes del Consejo de Aragón, en el del segundo en los registros oficiales turcos. Para definir la relación de los moriscos con los musulmanes de ultramar, ambos se sirvieron de la expresión "quinta columna», acuñada durante la guerra civil española ${ }^{6} \mathrm{y}$ divulgada luego en distintos países, lenguas y situaciones (por ejemplo, por Churchill en su célebre discurso "We shall fight on the beaches» ante los Comunes el 4 de junio de 1940), 7 para advertir de la potencial deslealtad de activistas que, abierta o clandestinamente, operaban desde dentro de un territorio en favor del enemigo exterior. Menos fatalista que Hess respecto a la amenaza morisca, ${ }^{8}$ la visión de Reglà, tal vez

ciana, Valencia, 200I, p. 2I (original de I6I8); Manuel Danvila y Collado, La expulsión de los moriscos españoles. Conferencias pronunciadas en el Ateneo de Madrid, edición, introducción y notas de R. Benítez Sánchez-Blanco, Universitat de ValènciaUniversidad de Granada-Universidad de Zaragoza, Valencia, 2007, p. 306 (original de I889); Carlos GarRiga, «Enemigos domésticos. La expulsión católica de los moriscos (I609-16I4)», Quaderni fiorentini per la storia del pensiero giuridico moderno, 38 (2009), pp. 225-287.

3. Fernand Braudel, La Méditerranée et le monde méditerranéen à l'époque de Philippe II, Armand Colin, París, 1949, pp. 590-593.

4. Joan REgLÀ, «La cuestión morisca y la coyuntura internacional en tiempos de Felipe II», en Estudios sobre los moriscos, Universidad de Valencia, Valencia, 1964, pp. 139-I57. Originalmente se publicó en Estudios de Historia Moderna, III (I953).

5. Andrew C. Hess, "An Ottoman Fifth Column in Sixteenth-Century Spain", The American Historical Review, 74-I (oct. 1968), pp. I-25.

6. Alexandre Koyré, La Cinquième Colonne, Allia, París, 1997, p. 8; Paul Preston, El holocausto español: odio y exterminio en la Guerra Civil y después, Debate, Madrid, 20II, p. 215.

7. «Parliament has given us the powers to put down Fifth Column activities with a strong hand, and we shall use those powers subject to the supervision and correction of the House, without the slightest hesitation until we are satisfied, and more than satisfied, that this malignancy in our midst has been effectively stamped out.» https://winstonchurchill.org/resources/speeches/I940-the-finest-hour/we-shall-fight-on-the-beaches/

8. "The Muslim fifth column in Spain served Ottoman purposes by diverting Habsburg energies toward the repression of an internal revolt while the Muslims took 
porque no se atiene tanto como aquel a la trágica experiencia granadina, apunta más a la posibilidad o predisposición de la minoría para cooperar con el corso turco-berberisco que a su efectiva capacidad para hacerlo:

Disidentes en materia religiosa y, por tanto, en tipo de civilización, los moriscos espańoles constituyeron siempre la "quinta columna» en potencia —en algunas ocasiones, incluso en acto-, vinculada a cualquier eventualidad de la lucha mediterránea entre los imperios hispánico y otomano. ${ }^{9}$

Cabría preguntarse si con la distinción aristotélica entre "potencia» y «acto» pretendía Reglà marcar la distancia que los moriscos estaban dispuestos a recorrer «siempre» y ante "cualquier eventualidad» para auxiliar a sus correligionarios y hermanarse en la lucha con ellos, aunque a la postre no pudieran lograrlo, o más bien, como parece sugerir unas páginas más adelante, que la condición de "quinta columna» era la "potencia» que, con otras palabras, les atribuían la Corona y las autoridades de los distintos reinos, que obraban de consuno para impedir precisamente su transformación en «acto». Sea como fuere, bajo el prisma del choque entre civilizaciones, Reglà, pese a conocer la advertencia de Braudel de que no hay un solo problema morisco, sino varios, y esbozar por ello con rapidez — era muy poco lo que se sabía en esas fechas - las diferencias demográficas, económicas, sociales y jurisdiccionales entre territorios, ${ }^{10}$ termina presentando a la minoría morisca como un bloque unido, determinado por su fe y su cultura, opuestas a las de los cristianos viejos que la someten.

Contra esta tesis, que Galmés de Fuentes llevaría mucho más lejos (y en su estela Harvey años después), al caracterizar a los moriscos

two of their major objectives, Cyprus and Tunis [...] Ottoman evidence provides enough information to indicate that imperial politics, transcending the Mediterranean, made the existence of the Morisco community a definite danger to the state». Hess, «An Ottoman Fifth Column», pp. 24-25.

9. ReGLÀ, «La cuestión morisca y la coyuntura internacional», p. I39.

IO. Ibidem, pp. I39-I43. 
como un todo homogéneo, una comunidad sin fisuras e inasimilable, ${ }^{\text {II }}$ ha escrito certeras objeciones Bernard Vincent. El paso del tiempo, que erosiona sin descanso con préstamos e intercambios de toda índole y múltiples controles y presiones el apego a las tradiciones islámicas y la capacidad de resistencia, variables el uno y la otra según los lugares y las circunstancias, es una de ellas. Como resultado — dice Vincent—, el mundo morisco es un puzle de gran complejidad. ${ }^{12}$ La existencia de colaboradores, que, a la vista de la degradación, buscan salvar tantos elementos de la identidad morisca como se pueda, y de colaboracionistas, quienes, por diferentes intereses, se muestran leales a la Corona en la hora crítica de la rebelión granadina (o, a menor escala, frente a la tentativa de alzamiento en Valencia en $\mathrm{I} 570)^{13}$ es otra prueba de la amplia diversidad de opciones. ${ }^{14}$ En las últimas décadas son numerosos los autores que han indagado sobre dicha diversidad y sus consecuencias a corto, medio y largo plazo. ${ }^{\text {Is }}$ Un buen ejemplo es el esquema de grados de asimilación que, inspirándose en Cervantes, propusieron en su día Magán y Sánchez González («finos moros» irredentos como Tiopieyo, posiciones vacilantes como las de Ricote, sinceras conversiones como las de las Ricotas ${ }^{16}$ y ha aplicado con solvencia Moreno Díaz en su

II. Álvaro Galmés de Fuentes, Los moriscos (desde su misma orilla), Instituto Egipcio de Estudios Islámicos, Madrid, I993; L. P. Harvey, Muslims in Spain, I50o to I6I4, University of Chicago Press, Chicago, 2005.

I2. Bernard VINCENT, "El río morisco», en El río morisco, Universitat de València-Universidad de Granada-Universidad de Zaragoza, Valencia, 2006, pp. I33-I35.

I3. Jorge Antonio Catalá Sanz y Sergio Urzainqui Sánchez, La conjura morisca de I570: la tentativa de alzamiento en Valencia, Biblioteca Valenciana, Valencia, 2009.

I4. Bernard Vincent, «Algunas voces más: de Francisco Núñez Muley a Fátima Ratal», en El río morisco, pp. 9I-93.

I5. Me remito a un par de estados de la cuestión que dan cuenta de tal producción historiográfica: Mercedes García-Arenal, «Religious Dissent and Minorities: The Morisco Age», The Journal of Modern History, 8I (2009), pp. 888-920; Enrique SorIA Mesa y Santiago Otero MondéJAR, «Una nueva encrucijada: la reciente historiografía sobre los moriscos», Tiempos Modernos. Revista Electrónica de Historia Moderna, 7, 2I (20IO), http://www.tiemposmodernos.org/tm3/index.php/tm/article/view/225.

I6. Juan Manuel Magán García, Ramón Sánchez González, Moriscos granadinos en La Sagra de Toledo, I570-I6I0, Caja de Ahorro de Toledo, Toledo, I993, pp. 
análisis de los moriscos antiguos y de los deportados granadinos en La Mancha. ${ }^{17}$ De ello se colige que el uso de la locución "quinta columna» para designar a la minoría morisca, incluso referida a un solo territorio o comunidad, como enteramente desleal a la monarquía y proclive a socorrer a los musulmanes de la otra orilla, es una exageración que no hace justicia a la realidad histórica.

No solo eso. Las fuentes judiciales, sobre todo los procesos criminales, han permitido conocer mejor las motivaciones, objetivos, estrategias, conexiones y tratos de los bandidos moriscos valencianos y, de resultas de ello, matizar considerablemente la idea de que las acciones delictivas de las cuadrillas solo cobran pleno sentido a la luz del enfrentamiento entre cristiandad e islam. Entre otras cosas, han revelado que los miembros de sus aljamas padecieron también sus depredaciones — razón por la cual se prestaron a cooperar en su desarticulación y castigo-, y que sus lazos y complicidades con turcos y berberiscos, que en la época se sospechaban intensas, fueron en realidad ocasionales. ${ }^{18}$ En esta misma línea, las declaraciones y relatos de testigos, tanto nuevos convertidos como cristianos viejos, que contienen algunos procesos incoados contra corsarios y presuntos infiltrados en el reino desafían por completo la tradicional percepción de las relaciones entre cristianos, moriscos y moros de la mar. En primer lugar, porque ponen de manifiesto que hubo nuevos convertidos que arriesgaron la vida (y hasta la perdieron) para evitar la captura de sus amigos o vecinos cristianos. En segundo lugar, porque ellos mismos fueron víctimas de las violencias de

26-29. Véase también al respecto Rafael Benítez SÁnchez-Blanco, «La historia de los moriscos en la obra de Cervantes. Apología de la expulsión, crítica de la limpieza de sangre», en M. M. Rabà, ed., Il Mediterraneo di Cervantes, I57I-I6I6, Consiglio Nazionale delle Ricerche, Istituto di Storia dell'Europa Mediterranea, Cagliari, 2018, pp. 37-55.

17. Francisco J. Moreno Díaz, Los moriscos de La Mancha. Sociedad, economía y modos de vida de una minoría en la Castilla moderna, Consejo Superior de Investigaciones Científicas, Madrid, 2009, pp. 359-387.

18. Jorge Antonio Catalá Sanz y Sergio Urzainqui Sánchez, El bandolerismo morisco valenciano (I563-1609), Universitat de València-Universidad de GranadaUniversidad de Zaragoza, Valencia, 2016. 
los corsarios, siendo compelidos a embarcar con destino a África cuando, pese a la opresión cristiana, preferían permanecer en sus tierras con sus familias. En tercer lugar, porque, una vez instalados en Berbería, algunos de estos emigrados contra su voluntad, descontentos con un sistema de poder y una sociedad donde no encontraban acomodo, buscaron la forma de regresar, jugándose de nuevo la vida y por partida doble, al hacer frente a la ira de las autoridades argelinas y a la vigilancia costera en Valencia. Y por último, porque todo ello ocurrió ya desde los primeros estadios del proceso de conversión y aculturación en la Corona de Aragón, durante el reinado de Carlos V, antes de que las campańas de evangelización y las presiones inquisitoriales comenzaran a dar frutos.

Escuchemos estas voces.

\section{La elección}

Es el día del Corpus de 1547 y el mar está en calma mientras Bertomeu Ferri regresa de Calpe a Gandía barajando la costa. Le acompañan a bordo de su barca el pelaire Francisco Alfonso, gandiense como él, Marçot, criado del señor de El Verger, dos nuevos convertidos de la ciudad ducal, Oix y Fabra, y un tercero de Oliva, llamado Taybet. No sabemos qué asuntos los han llevado a Calpe ni si traen mercancías o vuelven de vacío. Tampoco conocemos qué relación hay entre ellos, pero pronto va a quedar claro que los vínculos entre estos tres moriscos y el patrón, sea cual sea su origen y naturaleza, son profundos. Desde que han zarpado de Calpe otean el horizonte porque hay aviso de fustas de moros. Por fin, cuando están a punto de llegar a puerto y creen superado el peligro, divisan una embarcación, una nave corsaria en avanzadilla, que los enfila al instante. La huida no es una opción, porque es más rápida que la suya. Ferri duda, no sabe qué hacer. Entonces pregunta a los moriscos, no a los demás, sino a ellos específicamente, cómo ven la situación —así lo recuerda con detalle un año más tarde en su comparecencia ante la Audiencia de Valencia- Si nos precipitamos a hacer conjeturas, podemos sospechar que Ferri confía en que puedan interceder ante los moros para arreglar un acuerdo poco lesivo, acaso 
un rescate rápido en la orilla misma. ${ }^{19}$ Pero no, no es por eso por lo que les pide su opinión. Porque Oix, Fabra y Taybet le responden al unísono que, haga lo que haga, ellos están dispuestos a morir con él: «que fes lo que volgués, que ells morrien allà on ell, testimoni, morria». ${ }^{20}$

Enardecido por semejante declaración de lealtad, Ferri decide embestir a los corsarios, que, sorprendidos por la maniobra, viran para evitar su proa. Por un momento se siente a salvo, triunfante incluso — «los moros deixaren-los passar a la volta de terra, mostrant tenir-los por», dirá en I548 - , pero lo cierto es que apenas logra retrasar unos minutos un desenlace cantado. Al pasar a su lado los corsarios se han percatado de que no llevan más armas que unas espadas y se lanzan con fiereza en pos de su presa. Un disparo de ballesta alcanza al patrón en la pierna derecha. Otra saeta se le clava en un costado. Oix recibe un dardo en la espalda. Taybet tiene peor suerte: un bastonazo le parte el cráneo. Le quedan pocas horas de vida. No tiene sentido ofrecer más resistencia. En cuanto los moros suben a su barca y los apuntan con sus ballestas y escopetas, Ferri comprende que solo cabe rendirse y acepta que los trasladen hasta su fragata, unas millas más allá.

Pasarán el viernes y el sábado siguientes en las Peńas del Albir, cerca de la despoblada y mal defendida Benidorm, uno de los parajes predilectos de los corsarios para echar anclas cuando perpetran sus razias en el reino de Valencia. ${ }^{21}$ Antes, la misma noche del jueves, arrojan al mar el cadáver de Taybet. El sábado al atardecer, el arráez, que se llama Seysef Yayes y es oriundo de Xàtiva, permite a seis de sus tripulantes que desembarquen en la bahía de Altea. Cinco son moriscos valencianos que

19. Francisco Andújar Castillo, «Los rescates de cautivos en las dos orillas del Mediterráneo y en el mar (alafías) en el siglo XVI», en W. Kaiser, comp., Le commerce des captifs. Les intermédiaires dans l'échange et le rachat des prisonniers en Méditerranée, XVe-XVIIIe siècle, Ecole Française de Rome, Roma, 2008, pp. I54-I64.

20. Archivo del Reino de Valencia (ARV), Real Audiencia, Procesos, $3 \cdot{ }^{a}$ parte, Apéndice, 5643: declaración de Bertomeu Ferri, 9 de junio de 1548.

2I. Juan Francisco Pardo Molero, La defensa del imperio. Carlos V, Valencia y el Mediterráneo, Sociedad Estatal para la conmemoración de los centenarios de Felipe II y Carlos V, Madrid, 200I, pp. 178 y 42I. 
retornan de África a sus lugares de origen, el sexto es tagarino. Las correrías de este último, fácilmente identificable porque tiene dos pulgares en la mano izquierda, serán las que, doce meses después, constituyan el eje acusatorio del pleito por piratería y otros graves delitos en que habrá de testificar Ferri y nos permite reconstruir esta historia. Antes de zarpar hacia Cherchell, Yayes libera a los moriscos Oix y Fabra. Al cabo de unos días de estancia en aquella ciudad pondrá rumbo definitivo a Argel, donde Ferri permanecerá cautivo dos meses, hasta que en Gandía consigan reunir 270 libras para el pago de su rescate y otras 20 por el coste de curarle las heridas (del destino del pelaire Alfonso y Marçot nada se dice en el juicio).

Que tres moriscos se conjuren para defender a un cristiano viejo del ataque de corsarios berberiscos, uno de ellos pierda la vida en el empeño y otro la salve por centímetros no encaja en absoluto con el tópico de la alianza obstinada entre los nuevos convertidos y los moros de la mar. Uso el verbo "conjurar» deliberadamente, porque, como es sabido, tanto en Granada como en Valencia, los dos territorios más densamente habitados por moriscos, las autoridades aludieron de continuo en sus escritos a la Corona al entendimiento secreto entre aquellos y los enemigos de la otra orilla, sin el cual no habrían podido producirse las grandes fugas, los saqueos de poblaciones costeras y la captura de cristianos viejos ${ }^{22}$ (lo que no fue óbice para que el corso islámico y el negocio del comercio de cautivos persistieran después del destierro morisco)..$^{23}$

22. Julio Caro Baroja, Los moriscos del reino de Granada. Ensayo de historia social, Istmo, Madrid, 1983, pp. 169-I70; Tulio Halperin Donghi, Un conflicto nacional: moriscos y cristianos viejos en Valencia, Universitat de València, Valencia, 2008, pp. I09-II6 (edición original de 1955); VINCENT, «El peligro morisco», en El río morisco, pp. 65-74.

23. José Antonio Martínez Torres, Prisioneros de los infieles. Vida y rescate de los cautivos cristianos en el Mediterráneo musulmán (siglos XVI-XVII), Bellaterra, Barcelona, 2004; Maximiliano Barrio Gozalo, «El corso y el cautiverio en tiempos de Cervantes», Investigaciones Históricas: Época Moderna y Contemporánea, 26 (2006), pp. 8III4; Daniel Herschenzon, «Las redes de confianza y crédito en el Mediterráneo occidental: cautiverio y rescate (I580-1670)», en F. P. Guillén y S. Trabelsi, dirs., Les 
No es necesario insistir en que el peligro era real y recurrente. Solo en el tramo litoral mencionado en el relato de Ferri, entre Benidorm y Gandía, hay constancia de que las naves corsarias se presentaron al menos una decena de veces desde el decreto de conversión forzosa hasta el año en que este prestó declaración. Algunas de aquellas acciones dejaron una huella indeleble en la memoria colectiva. En octubre de I529, más de medio millar de turcos de la armada de Cachadiablo desembarcaron en el río de Altea y, guiados por moriscos de la zona, penetraron tierra adentro, entre las sierras de Bernia y Laguar, para llevarse consigo a los nuevos convertidos de Murla, baronía del conde de Oliva, y de Parcent, cuyo señor, Pere de Perandreu, al igual que otros moradores cristianos, fue hecho prisionero y trasladado a Argel. ${ }^{24}$ Aún más espectacular fue la operación de Salah Rais en agosto de I532, cuando, faltos de otros auxilios, el duque de Gandía y el conde de Oliva trataron en vano de impedir con su caballería que cientos de corsarios turcos condujeran hasta la playa de Cullera, donde esperaban sus galeras, a más de dos mil moriscos de la Valldigna. ${ }^{25}$ Seis años después, una poderosa armada otomana bajo el mando de Axe Baxá, lugarteniente de Barbarroja, sembraría de nuevo el pánico en la comarca de la Marina al internarse sus hombres en el valle de Xaló $\mathrm{y}$, sin obstáculo aparente, embarcar en sus fustas, fondeadas a la vista de todos en Calpe, a más de un millar de moriscos de aquella baronía

esclavages en Méditerranée: Espaces et dynamiques économiques, Casa de Velázquez, Madrid, 20I2, pp. I3I-I4O; Francisco Velasco Hernández, Corsarismo, piratería y guerra costera en el Sureste español. El acoso turco berberisco a las costas de Alicante, Murcia y Almería en los siglos XVI y XVII, Ediciones Nova Spartaria, Murcia, 2019.

24. Diego de Haedo, Topografia e historia general de Argel, Sociedad de Bibliófilos Españoles, Madrid, 1927, p. 252; Pardo Molero, La defensa del imperio, p. 247; y La guerra i els cavallers. Els Centelles, el comtat d'Oliva i la defensa del Regne de València, CEIC Alfons el Vell, Gandía, 20II, pp. 63-64.

25. Eugenio Císcar Pallarés, La Valldigna, siglos XVI-XVII. Cambio y continuidad en el campo valenciano, Diputación de Valencia, Valencia, 1997, p. 220; PARDo Molero, La defensa del imperio, pp. 275-277; Santiago La Parra López, «Moros en la costa..., a los cuatrocientos años de la expulsión", Revista de Historia Moderna. Anales de la Universidad de Alicante, 27 (2009), pp. 169-170. 
y otros lugares próximos. ${ }^{26}$ Volveremos sobre estos tres episodios más adelante.

La propia historia que cuenta Ferri a los jueces reúne, por supuesto, elementos inherentes a la amenaza de la correlación islámica: la brutalidad con que se emplean los corsarios para capturar a sus víctimas; el conocimiento que el arráez setabense tiene de la costa de su reino natal; la pertenencia a la tripulación de moriscos emigrados, varios de los cuales, cabe imaginar que no por azar, son originarios de la zona donde se lleva a cabo la expedición (Alcoleja, Polop, Gandía, Oliva). ${ }^{27}$ Las peripecias de uno de estos tránsfugas en particular, Joan Tagarí, apodado Mahomadico dels Dos Polzes, principal encausado en el proceso de I548, ponen al descubierto otros datos de interés. Para empezar, la sorpresa de que Ferri lo conoce de un encuentro anterior, en el que además lo toma por cristiano. Así lo manifiesta en su declaración:

[...] conegué en lo dit vexell dels moros hun tagarí que té dos polces en una mà, que.l ohí nomenar Mahomadico, lo qual havia mig any, poch més o menys, que el trobà prop de Cullera e vingué fins a València en companyia de ell, testimoni; e ell, testimoni, lavors se cregué que era cristià.

Nada hay en la fisonomía, forma de hablar y conducta de Tagarí, y es obvio que tampoco en su indumentaria, que delate a ojos de los cristianos viejos que no es uno de ellos, no al menos antes de marcharse a Berbería y regresar armado y vestido a la turquesca. Ferri ha recorrido junto a él toda una jornada de trayecto en enero de 1547 sin darse cuenta de que es un nuevo convertido. La anécdota es indicativa de algo que ha sido señalado por los historiadores: la dificultad de distinguir a partir del aspecto externo y los caracteres físicos entre los cristia-

26. Pardo Molero, La defensa del imperio, p. 3 I8.

27. Según confiesa bajo tortura uno de los corsarios, Çahet Razín, natural de Algimia de Almonacid, del medio centenar de hombres embarcados en la fragata unos treinta eran alarbes y el resto emigrados del reino, entre los que había varios de Gandía y Oliva. ARV, Real Audiencia, Procesos, 3. ${ }^{a}$ parte, Apéndice, 5643: acto de tormento judicial, 22 de junio de 1548 . 
nos viejos y los moriscos de algunas comunidades $\mathrm{y}$, por ende, de vigilar a los segundos si es menester. ${ }^{28}$

Además de ser interrogado por la justicia de Càrcer, donde el señor del lugar en persona lo atrapa el i de junio de I548 cuando buscaba a hurtadillas en un campo algo que echarse al coleto, Mahomadico comparece ante los magistrados de la Audiencia de Valencia hasta cinco veces en dos semanas. Es carne de cadalso desde el principio, ${ }^{29}$ pero solo con el paso de los días parece tomar conciencia, abrumado por el peso de las pruebas testificales y materiales que lo incriminan, del destino que le aguarda. Por eso quizá su versión de los hechos va haciéndose cada vez más precisa (lo que no significa que sea necesariamente más creíble). En su primera confesión de oficio, el 8 de junio, revela que había nacido en Burbáguena y que había cruzado la frontera de Aragón quince o dieciséis años atrás. Pasó luego otros doce en el ducado de Segorbe, donde residió y trabajó con normalidad — «no entengué en fer cosa leja», dice_-, hasta que un morisco de Riba-roja lo persuadió para irse a tierra de moros. A preguntas de la fiscalía niega haberse dedicado al corso luego de su llegada a Argel y declara que si finalmente aceptó subirse a la fragata de Yayes para venir al reino de Valencia fue porque el alcaide de Argel le había pedido que le trajera dos perros de muestra. Hay razones para sospechar que esta historia de los perros es inventada o, por mejor decir, adaptada, ${ }^{30}$ pero en ese trance judicial la compra que alega haberle encomendado tan alta au-

28. Bernard VInCEnT, «¿Cuál era el aspecto físico de los moriscos?», en Andalucía en la Edad Moderna: economía y sociedad, Diputación Provincial, Granada, 1985, pp. 303-313; Moreno Díaz, Los moriscos de la Mancha, pp. 286-288.

29. Fue ejecutado el 3 o 4 de julio. Cfr. Pablo Pérez García y Jorge Antonio Catalá Sanz, «La pena capital en la Valencia del Quinientos», en Conflictos y represiones en el Antiguo Régimen, Universitat de València, Valencia, 2000, p. 76.

30. Otro de los imputados en el proceso, Ubaydal Ferrer, un joven morisco de Gilet, menor de veinte ańos, con quien Mahomadico comparte espera en la sierra de Bernia hasta que una fusta los pueda llevar a Argel, alega haber abandonado aquella baronía porque había tenido una disputa con el procurador del señor sobre la posesión de una perra de muestra. ARV, Real Audiencia, Procesos, $3 .{ }^{a}$ parte, Apéndice, 5643: confesión de oficio de Ubaydal Ferrer, is de junio de I548. También se refie- 
toridad sirve para justificar por qué después de su desembarco en Altea pasó varios meses deambulando por Aragón (Calamocha, Belmonte, el condado de Aranda...). Eso no significa que los procuradores fiscales, que han averiguado por otras fuentes que portaba cartas de Argel, se traguen el cuento. En cualquier caso, como no levantan la liebre ni le apremian a decir la verdad, Tagarí concluye la narración de su periplo con el retorno desde Aragón al punto de partida: las montañas de la Marina desde las que se divisan los fondeaderos de las fustas corsarias, donde acaba por unirse a dos nuevos convertidos que se le antojan más osados que el resto de los que se han congregado para cruzar el mar: Çahet Daraze de Alcoleja y Omaymat Bohamir de Gestalgar. $^{31}$

Lo que confiesa haber hecho junto a ellos en los meses siguientes convence a los jueces de que merece un castigo ejemplar. Con una naturalidad pasmosa, Mahomadico reconoce que, habiendo simpatizado con Çahet y Omaymat, «se'n tornaren dins terra a cativar cristians e fer lo mal que porien». Tal vez no quiera decir eso, más bien que esa era la intención de sus camaradas, pero estas son las palabras exactas que el escribano pone en su boca y por las que será descuartizado después de su ejecución. Porque, en efecto, Tagarí desvela que en unos pastos entre Chiva y Torrent secuestraron a un joven cristiano de apenas trece ańos y que, después de que Omaymat asesinase con alevosía al boyero para el que trabajaba, llevaron al chico consigo hasta la sierra de Bernia, donde esperaron en balde durante dos meses una oportunidad para embarcarse. En torno a esos crímenes gira sobre todo el interrogatorio al que es sometido por el tribunal los días 9 y is de junio. Entre ambas fechas, Çahet, que ha sido apresado semanas antes en aquellas mismas cinglas por los cristianos de Callosa, pone en conocimiento de los magistrados que, según le contó el propio Mahomadico, la causa de que se enrolara en la nave de Yayes era que un tagarino establecido en Argel le había ofrecido 30 coronas por traerle a su hijo, criado de un herrero

re al animal en cuestión Diego de Salazar, criado de la seńora de Gilet, en su declaración de 29 de junio.

3I. Ibidem, primera confesión de oficio de Joan Tagarí, 8 de junio de I548. 
morisco, aragonés como ellos, con casa en Valencia. Sin embargo, pese a correr el riesgo de ir a la ciudad (riesgo ciertamente alto, si lo hizo cubierto con la llamativa ropa que vestía al ser detenido en Càrcer: un jubón rosado dos palmos más grande que su talla, un birrete negro, otro sombrero colgando, una calabaza al cinto), ${ }^{32}$ Mahomadico no pudo lograr su objetivo. Enterado de que aquel herrero tenía amores con una cristiana, a la postre tuvo miedo de proponerle, por si lo delataba, que dejara marchar al muchacho para que pudiera reunirse con su padre en Argel. ${ }^{33}$

Una vaina de cuchillo — como «de ganivet de frare o de capellà»—, que se le incauta a Tagarí en el momento de su arresto y que afirma haber recibido de Omaymat Bohamir es, seguramente, la razón principal de que el 22 de junio haya de personarse por última vez ante los jueces. Estos no dudan de su culpabilidad, pero, sabedores para entonces por otros testigos de la implicación de Bohamir en el saqueo del monasterio de Santo Espíritu de Gilet en septiembre de 1547, con el que dicha vaina vincula al reo de forma involuntaria, optan por arrancarle bajo tormento cualquier información que pueda proporcionarles sobre el suceso, uno de los hitos del corso turco-berberisco en el reinado de Carlos V, no tanto por los estragos ocasionados como por su carga simbólica. La confesión de Tagarí corrobora, como consignan los archivos de la época y refiere en su crónica Escolano, que en el asalto colaboraron los moriscos de Gilet y alrededores. ${ }^{34}$ Por lo que a Omaymat en concreto concierne, Tagarí afirma haber oído de sus labios que descendió de una galeota musulmana en el grao de Sagunto junto con otros cuatro moriscos valencianos y un par de aragoneses con la misión de subir hasta una cima próxima al cenobio y encender hogueras para orientar a los corsarios, y que, una vez dentro, robaron algunas alhajas y capturaron a varios frailes. No obstante, puestos sobre aviso, los de

32. Ibidem, declaración de Joan Carròs, señor de Càrcer, 3 de junio de 1548 .

33. Ibidem, confesión de oficio de Çahet Daraze, I3 de junio de 1548.

34. Gaspar Escolano, Segunda parte de la Década primera de la Historia de la Insigne y Coronada Ciudad y Reyno de Valencia, Valencia, I6II, cols. I755-I756; PARDO Molero, La defensa del imperio, p. 39I. 
Sagunto y la guardia de a caballo los obligaron a dispersarse cuando regresaban a sus barcos. ${ }^{35}$

Omaymat es el último de los tres compinches que depone ante la Audiencia, el 7 de septiembre de 1548, a punto de cumplirse un año de aquel saqueo. Han pasado dos meses desde la ejecución de Tagarí y Daraze, ${ }^{36}$ justo el tiempo que ha estado encerrado en Murla, donde lo prenden mientras merodea en compañía de un turco furtivo. Ese mismo día, el tribunal escucha su confesión sobre el escrito de denuncia de los fiscales, en la que apenas aporta novedades, y, a renglón seguido, la declaración de un último testigo. Su confesión de oficio, preceptiva, solo se ańade a la causa después de que se le haya dado tormento el día 22, lo que transluce cierta desidia en el procedimiento, toda vez que la vindicta pública ya ha sido en gran medida satisfecha con la muerte de sus cómplices y de otro par de empapelados: Pedro Castellano Gaurí y Çahet Razín, igualmente por corso y pretender pasarse a Berbería. ${ }^{37}$ Sea como fuere, y pese al rigor de la tortura, Omaymat persevera hasta el final en negar las acusaciones y admite únicamente haber robado unas ollas de cobre en la cocina del monasterio ańos antes del asalto. ${ }^{38}$ Es gracias al postrer testigo convocado, Fernando de Ribera, escudero de Elionor d'Íxer, señora de Gilet, como los jueces averiguan que, aunque

35. ARV, Real Audiencia, Procesos, $3^{\text {a }}$ Parte, Apéndice, 5643: tormento judicial de Joan Tagarí, 22 de junio de I548.

36. Daraze fue ejecutado el mismo día que Tagarí (ARV, Real Cancillería, I322, 4V y I2v). Había llegado al reino desde Cherchell en la fusta del arráez Mahomat Tanax de Fez, quien, poco después de ordenarle desembarcar cerca de las Peñas del Albir para inspeccionar el terreno, se dio a la fuga precipitadamente para escapar de las galeras de Bernardino de Mendoza, dejando a Daraze a su suerte. Sus andanzas en los meses siguientes hasta que tropezó con Omaymat son dignas de ser contadas con mayor detalle. Pese a ser torturado el 22 de junio, no añadió nada a lo que había revelado en su confesión de oficio el día I3 de ese mes.

37. Castellano era de Algar, aldea de Callosa d'En Sarrià; Razín de Algimia de Almonacid. ARV, Real Cancillería, I322, 4 v; ARV, Maestre Racional, 8867, 5or.

38. ARV, Real Audiencia, Procesos, $3 .^{\text {a }}$ parte, Apéndice, 5643: confesión sobre la denuncia de Omaymat Bohamir, 7 de septiembre de 1548; tormento judicial, 22 de septiembre; confesión de oficio, 24 de septiembre. 
nacido en Gestalgar, Omaymat llevaba casi una década instalado en Gilet cuando cometió el citado delito, por el que el dueño de la baronía lo condenó a la horca en I543 o I544. Con todo, a ruegos de los frailes, accedió a última hora a conmutar la pena por la de azotes, después de lo cual Omaymat se trasladó a Yátova, donde lo acogió el alamín, y desde allí se fugó a Argel. ${ }^{39}$ Ese es, por consiguiente, el origen de su resentimiento hacia los cristianos viejos y, en particular, hacia los religiosos y los barones de Gilet, y la causa última de su fogosa cooperación con los moros de la mar, que terminaría costándole la vida.

En suma, el abanico de posturas que afloran en el proceso contra Joan Tagarí y sus compañeros de fechorías venidos de Argel en torno a las relaciones entre moriscos y cristianos viejos es muy amplio. En un extremo hallamos a Bohamir, Daraze y, aunque disimule su hostilidad, el propio Mahomadico. También a los citados Pedro Castellano Gaurí y Çahet Razín, que parecen haber participado de grado en las empresas corsarias. No digamos el arráez Yayes y otros naturales del reino enrolados en su tripulación que regresaron a Berbería sin contratiempos. En sus antípodas encontramos a Oix, Fabra y Taybet, que anteponen, apostando la vida en ello, la amistad, la lealtad, la obediencia o cualquiera que sea la causa que los ata al cristiano viejo Bertomeu Ferri a la solidaridad con sus correligionarios tránsfugas y con los musulmanes de la otra orilla. No es fácil documentar ejemplos similares. El episodio trae a la memoria aquel otro acaecido en Altea veinte ańos antes, en enero de I528, cuando Vicent Adrover, vecino de Callosa, un morisco que lo acompańaba y un pastor con el que se tropezaron en el camino eludieron la emboscada de unos corsarios gracias a la repentina aparición de un moro desembarcado de su fusta (y tal vez extraviado) que les advirtió del peligro y se entregó sin plantar cara. ${ }^{40}$ Décadas después, durante el asalto a la villa almeriense de Tabernas, en septiembre de 1566 , en el que los piratas berberiscos cautivaron a medio centenar de cristianos, el mercader morisco Hernando Arrabiha, con tienda en

39. Ibidem, declaración de Fernando de Ribera, 7 de septiembre de 1548.

40. Pardo Molero, La defensa del imperio, pp. 227-228. 
aquella población, se arriesgó a esconder al hijo de un capitán y a dos mujeres cristianas para evitar que los llevaran a sus naves, fondeadas entre las playas de Las Negras y Agua Amarga. Meses más tarde, el día de Jueves Santo de 1567, Martín Ramón Alhaziz, morisco de Gádor, participó junto con el cristiano Diego Dávila en la búsqueda por los barrancos de La Garrofa de los moros que habían capturado a una docena de vecinos de Quiciliana, lugar próximo a Almería, hasta que dieron con uno de aquellos. ${ }^{41}$

Entre ambos polos opuestos asoman actitudes y situaciones intermedias, como la del herrero tagarino que, enamorado de una cristiana, despierta recelos en Mahomadico. O como la de un joven morisco de Antella que, al cruzarse con Çahet Razín y Ubaydal Ferrer cuando se dirigen a las montañas de Bernia, responde a su petición de alimento que no los auxiliará si son «gent de la mar»; solamente cuando Razín le asegura no serlo se aviene a conducirlos hasta un «home de bé» que les presta socorro, ${ }^{42}$ lo que confirma que el muchacho desconfía de los corsarios musulmanes, probablemente porque sus actuaciones, incluso si precedía concertación con las aljamas para la huida, implicaban el uso de la fuerza. Así lo explicita pocos años más tarde Çabdonet, nuevo convertido de Callosa d'En Sarrià capturado en I557 después de que la fragata en la que se había embarcado en Cherchell naufragase frente a la Albufera de Valencia. Interrogado sobre las circunstancias en que se había pasado a Berbería, Çabdonet contesta que, ocho años antes, cuando pescaba en la playa de Altea, había sido obligado por los moros a subirse a una fusta y dejar atrás a su mujer, hijos, casa y bienes («no pogué fer altre sinó enbarcar-se»). Solo ahora se había aventurado a venir a robar al reino como subterfugio para regresar con su familia. ${ }^{43}$ Tres décadas después, la señora de aquella baronía, Luisa de Moncada,

4I. José Ángel TAPIA, «La costa de los piratas», Revista de Historia Militar, 32 (1972), pp. 97-99.

42. ARV, Real Audiencia, Procesos, $3 \cdot{ }^{\mathrm{a}}$ parte, Apéndice, 5643 : confesión de oficio de Çahet Razín, Is de junio de 1548.

43. ARV, Real Audiencia, Procesos, $3 .{ }^{a}$ parte, Apéndice, 5206: confesión de oficio de Çabdonet, 26 de mayo de 1557. 
comunicaba a la Corona que sus vasallos moriscos de Callosa, Micleta y Algar se habían marchado a Argel en I584, junto con los de otras poblaciones de la zona, "parte de voluntad, parte por fuerza». ${ }^{44}$ Enfrentados, pues, al dilema de optar entre tierra y fe, como gráficamente plantea Bernard Vincent, ${ }^{45}$ fueron muchos más, a tenor de las noticias de que disponemos, los moriscos que, si se les presentó ocasión, renunciaron a la primera en beneficio de la segunda. Pero ¿cuántos como Çabdonet tuvieron que seguir esa senda constreńidos por los corsarios pese a sus deseos de permanencia?

\section{Volverse aquende}

Un interesantísimo proceso criminal conservado de forma un tanto rocambolesca da algo de luz sobre este fenómeno escurridizo. En julio de I55I, el tercer marqués de Denia, Luis de Sandoval y Enríquez, y los procuradores patrimonial y fiscal del rey se enredaron en un litigio a propósito de los bienes pertenecientes a un grupo de moros de Cherchell cuya barca había quedado varada en la playa de Xàbia. Alegaba el influyente don Luis ${ }^{46}$ que, como habían encallado en la costa de sus dominios, debía serle asignada la propiedad de todo cuanto aquellos traían consigo. Por el contrario, los procuradores regios reclamaban los haberes, ropa y comida que se había incautado a los apresados en la orilla, porque eran enemigos infieles a los que las corrientes marinas, los caprichos del viento y su impericia en el arte de navegar habían terminado por arrastrar hasta ese punto del litoral cuando en realidad querían ir a Argel. Pero para que los jueces de la Audiencia fallasen a su

44. Pascual Boronat y Barrachina, Los moriscos españoles y su expulsión. Estudio histórico-crítico, Imprenta de Francisco Vives y Mora, Valencia, I9OI, tomo I, p. 313; PARdo Molero, «¿Emigrantes o conspiradores?», p. 206.

45. Bernard Vincent, El río morisco, p. I42.

46. Bernardo J. García García, «Los marqueses de Denia en la Corte de Felipe II: linaje, servicio y virtud», en J. Martínez Millán, dir., Felipe II (I527-I598): Europa y la monarquía católica, Parteluz, Madrid, I998, vol. 2, pp. 305-322. 
favor debían probar que aquella singular tripulación que incluía más mujeres y niños que hombres adultos constituía una amenaza cierta para la paz pública. De ahí que, aunque no era estrictamente necesario, ${ }^{47}$ se insertase en la causa copia del procedimiento tramitado a instancia de los fiscales. ${ }^{48}$

Lo primero que llama la atención y contradice la pretensión del fisco regio es la composición del grupo de personas detenidas: cuatro hombres, tres de ellos oriundos del reino, sus respectivas esposas, una viuda de Callosa d'En Sarrià, una sexta mujer nacida en Cherchell cuyo marido no había podido embarcarse, y dos cristianas viejas, además de siete niños menores de trece años, que habían quedado, al igual que sus madres, bajo la tutela del médico morisco Adam Xubrich, quien solía intervenir como intérprete en los interrogatorios a reos que no hablasen aljamía. ${ }^{49}$ Las historias que irían destapando ante el tribunal y el hecho constatado de que se hubieran proveído de alimentos para varias semanas acabarían de convencer a los magistrados de que, como protestaban, habían venido voluntariamente al reino para hacerse cristianos y vivir como tales, y no por azar, ni víctimas de su presunta torpeza náutica, ni con un propósito maligno, como denunciaba la fiscalía.

Quizá porque el relator de la causa, el oidor interino Joan Baptista Paredes, ${ }^{50}$ las creyese más dignas de crédito que a sus compañeros de travesía muslimes, quiso empezar por tomar testimonio, el 8 de agosto,

47. En algunos pleitos se encuentran copias, íntegras o parciales, de otros procesos con los que guardan relación, pero es mucho más habitual que las partes se limiten a hacer mención de la resolución o de alguna de las diligencias judiciales realizadas. Debo el conocimiento de esta pieza a Sergio Urzainqui, a quien reitero aquí, como en tantas otras cosas, mi agradecimiento.

48. ARV, Real Audiencia, Procesos, 2. ${ }^{a}$ parte, Letra P, 58.

49. Barceló y Labarta reproducen algunas cartas suyas de los años treinta. Cfr. Carmen Barceló y Ana Labarta, Archivos moriscos. Textos árabes de la minoría islámica valenciana, I40I-I608, Universitat de València, Valencia, 2009, pp. 205-210.

50. La Real Audiencia atravesaba en esas fechas una situación muy delicada a causa de la separación del Regente de la Cancillería y del procesamiento de varios magistrados entre I548 y I550. Teresa CANET APARISI, La magistratura valenciana (siglos XVI-XVII), Universitat de València, Valencia, 1990, p. I58; y «Entre la visita y la 
a las dos mujeres cristiano-viejas: Isabet Tristany de Elche y Caterina Cros, nacida en la pequeña localidad de Palanques, en el Maestrazgo, limítrofe con la raya de Aragón. Podemos imaginar la sorpresa del juez al escuchar a Isabet responder que ignoraba si estaba bautizada, ya que nunca conoció a sus padres. Desde muy niña había estado en casa del mercader ilicitano Tristany, al cual debía su crianza y su apellido, hasta que la entregó en matrimonio al maestro Alonso Sabonet. Hacía un lustro que los moros habían capturado a un hijo suyo y, echándolo en falta, había abandonado el domicilio familiar tiempo atrás y comenzado a pedir limosna por el reino para rescatarlo. Se hallaba en la aldea de Santa Coloma, en el valle de Segó, cuando unos corsarios la raptaron junto con otros cristianos, entre quienes figuraba Caterina Cros. Ya en Argel, la suerte, que le había sido esquiva hasta entonces, se alió con ella: bien fuese porque su piel era oscura, ${ }^{\text {I }}$ bien porque juró ser hija de una mora, la dejaron en libertad y le permitieron vagar por donde quisiera, y así pudo localizar a su hijo, que había renegado. Es un enigma si las cosas sucedieron tal y como las cuenta Isabet o, al contrario, su hijo había emigrado para apostatar y ella porfió en encontrarlo y traerlo de vuelta. Fuera como fuese, lo cierto es que meses más tarde se tropezó de forma fortuita con Caterina en la ciudad de Cherchell y cuando esta le dijo que se había confabulado con unos moros para embarcarse hacia Valencia, lloró de júbilo por poder regresar "per salvar la sua ànima». ${ }^{22} \mathrm{Al}$ comparecer por segunda vez ante la Audiencia, en octubre, Isabet agregaría que en la nave venían todos «los més alegres del món».53

sucesión. La resistencia a la virreinalización administrativa en Valencia entre Carlos V y Felipe II», Estudis. Revista de Historia Moderna, 28 (2002), pp. 207-209.

5I. Sobre la importancia del color de los esclavos, véase Aurelia Martín CaSaRES, «Esclavitud y mentalidad: la población esclava de Granada a lo largo del siglo XVI», Chronica Nova, 25 (1998), pp. 337-348; y La esclavitud en la Granada del siglo XVI. Género, raza y religión, Universidad de Granada, Granada, 2000.

52. ARV, Real Audiencia, Procesos, 2. ${ }^{a}$ parte, Letra P, 58: confesión de oficio de Isabet Tristany, 8 de agosto de I55I, Ir-2V.

53. Ibidem, 59r-6or. 
No menos dramático y sobrecogedor es el relato de Caterina Cros. Huérfana como Isabet, al cumplir cinco años su hermano mayor la había puesto bajo custodia del Pare d'Òrfens. ${ }^{54}$ Después de prestar servicio a diversos amos y de casarse con el criado de un boticario que un buen día la dejó tirada en Valencia, Caterina se las ingenió para salir adelante e incluso consiguió comprarse una casita en Santa Coloma. Allí la habían capturado la víspera de San Juan del año anterior unos moros, cuya fusta formaba parte de la armada otomana de Alí Amet..5 Al llegar a Argel se libró de ser vendida porque se le ocurrió decir que era tagarina y, milagrosamente, un morisco aragonés llamado Obaydal proclamó que, en efecto, aquella era su esposa. Solidario y generoso, Obaydal buscó la mediación del mercader valenciano Vidrier, a la sazón en la ciudad, quien, al ver desconsolada a Caterina, se apiadó de ella: «per amor de vos, que m'obligaré al que jamés me fora obligat, perquè yo $\cdot \mathrm{m}$ descararé al alcalde Ramadán (sic), que és molt mon amich». Pero aunque logró cerrar un trato con el alcaide, no pudo vencer la oposición del arráez Morat, que había apresado a Caterina en Santa Coloma y se negaba a permitir su salida de Argel precisamente porque la creía tagarina: «no la [h]y havia volguda vendre, dient que ella, dita confessant, era tagarina y que, [essent] tagarina, no.s podia vendre». ${ }^{56}$

Si no podía hacerse por las buenas, se haría por las malas. Sin manifestarle que Caterina era cristiana, el tenaz Obaydal, que para entonces ya tenía planeado retornar a España, se concertó con un tagarino de Calanda para que los condujese hasta Cherchell, donde otro paisano los hospedó por un tiempo. Advertido de su huida, no tardó Morat en hacer detener a Obaydal, aunque finalmente, gracias a la intercesión de un renegado, accedió a perdonarlo: «feu que aquell dit Ovaydal — cuenta Ca-

54. Francisca Aleixandre Tena, «Orfes, expòsits i orats. Aproximació a l'estudi de la marginació a València durant l'Edat Moderna”, Afers, 3 (5-6), (1987), pp. 47-I05.

55. A principios de junio de 1550 las autoridades valencianas estaban avisadas de la inminente llegada de la escuadra de Alí Amet. Pardo Molero, La defensa del imperio, p. 406.

56. ARV, Real Audiencia, Procesos, $2,{ }^{\text {a }}$ parte, Letra P, 58: confesión de oficio de Caterina Cros, 8 de agosto de I55I, 2V-5v. 
terina-, li besàs les mans y los peus, y sellavors lo dit Morat arrahis dix al dit Ovaydal [...] que per què se'n volia tornar a terra de crestians, que no u esmentàs més; si no ell lo faria castigar». Meses después, desprevenido o quizá ausente el capitán corsario, Obaydal anunció a Caterina su intención de embarcarse de inmediato y le prometió arreglar las cosas para rescatarla. En casa de un moro llamado Modegel, donde la colocó como criada, Caterina, viendo que su ama tenía buen corazón, le confesó su deseo de volver a Valencia. Fue ella quien la puso en contacto con unos moros naturales del reino que proyectaban regresar a su tierra: Alí Payol de Polop y Suleimén Ballau de Senija. Ambos quedaron impresionados al oír decir a Caterina que conocía al capitán Gaspar Sanç de Benidorm y que este podía guiarlos hasta el gobernador y el inquisidor, ${ }^{57}$ por lo que resolvieron invitarla a unirse, no sin instarla a guardar el secreto. No podía imaginar que el destino le reservaba un último infortunio: habiendo enfermado, una noche invocó entre calenturas a la Virgen de Montserrat, y otra criada de la casa, alarmada por los rezos, la denunció a la justicia, que se la llevó presa. Enterado de su encierro, pocos días después Payol ofreció cuarenta doblas para excarcelarla (lo que prueba la importancia que Caterina había cobrado para el éxito de la operación). No había tiempo que perder. Sin esperar a que estuvieran listos para evadirse todos los conjurados, reunieron a sus familias y a otras personas que estaban avisadas, además de Caterina y su amiga Isabet, y se subieron a la barca de Martí Zacarra, con la que transportaba mercancías entre Cherchell y Argel. Antes de que los centinelas de la playa pudieran descubrirlos, zarparon de noche hacia la costa de Valencia. ${ }^{8}$

$\mathrm{Al}$ reconocer que sin su ayuda, no por interesada menos humana, les habría sido imposible volver salvas al reino, Isabet y Caterina abo-

57. Aunque de este modo Caterina obtuvo el pasaje, poca ayuda habría podido prestarles el capitán Sanç. Tanto si lo conocía de verdad, como si solo había oído hablar de él, lo cierto es que Gaspar Sanç y su guardia habían abandonado el castillo de Benidorm por orden del duque de Calabria en julio de i547. Cfr. Pardo Molero, $L a$ defensa del imperio, p. 384.

58. ARV, Real Audiencia, Procesos, 2. ${ }^{\mathrm{a}}$ parte, Letra P, 58, 6r-7v. 
naban la tesis de los imputados de que habían salido de Cherchell para vivir como cristianos. Es significativo, en este sentido, que en sus confesiones de oficio, recibidas el i2 de agosto, tanto Zacarra, dueño de la embarcación, como Payol y Ballau, organizadores de la escapada, jurasen como cristianos y no como moros, haciendo patente desde el principio su voluntad de ser considerados sinceros conversos. La pregunta inevitable a la que, en consecuencia, debían contestar de forma satisfactoria y concluyente era por qué entonces se habían pasado a tierra de infieles. Sus respuestas hacen hincapié en una misma idea, que cabe subrayar con énfasis: porque no habían tenido elección. Zacarra, vasallo del conde de Oliva pero criado en La Valldigna, es quien más se lamenta de haberse marchado: «si ell sabera sellavors lo que ara sab, no hu fera» — dice contrito- , pero no le quedó más opción: siendo menor de veinte años, un tío suyo se lo había llevado cuando la armada de Salah Rais vino para trasladar a Argel a los nuevos convertidos del valle de Alfandec, en el verano de 1532.59 También Ballau afirma haberse ido con su mujer por la fuerza, seis años más tarde, con ocasión de la razia de Axe Baxá en el valle de Xaló. ${ }^{60}$ Payol no recuerda con exactitud la fecha en que partió a Berbería, aunque, después de titubear, agrega que «se n'anaren en allende quant Cachadiablo se'n portà la gent de Callosa a Sarcell», ${ }^{61}$ esto es, en 1529 . He aquí citadas en tres declaraciones sucesivas tres de las expediciones otomanas sobre la costa valenciana más memorables del reinado de Carlos V, tres ejemplos formidables de fugas a gran escala propiciadas por los enemigos de ultramar, pero también violentadas y acrecentadas por estos.

Sin embargo, al menos uno de estos tres reos no dice la verdad. Basta cotejar su confesión de oficio con las alegaciones de su procurador, Miquel Jeroni Climent, meses más tarde, el I6 de noviembre, para darse cuenta de que Payol no salió del reino en 1529 con la escuadra de Cachadiablo, sino en circunstancias aún más trágicas, a raíz de la matanza perpetrada en Polop por los agermanados de Vicent Peris en el

59. Ibidem, 8v-Ior.

6o. Ibidem, IIr-v.

6I. Ibidem, Ior-IIr. 
verano de I52I. ${ }^{62}$ Así lo expone Climent, haciendo referencia expresa a su defendido:

venint lo dit camp de la germania a la dita baronia de Polop, entraren en dit castell e mataren alguns dels moros o moriscos que estaven en lo dit castell, com és cosa notòria; e axí mateix, volent matar al dit Perot Payol, li pegaren diverses coltellades, de les quals se poden veure en la persona de aquell los senyals e cicatrius, e dexaren aquell per mort, essent aquell chic y de menor edat.

Y añade a continuación:

havent sabut alguns moros de allende de les parts de Àfrica, los quals tenen amichs e parents en lo present regne, com lo camp dels agermanats venia contra los dits moriscos de la baronia de Polop e valls circumvehïnes de aquella, armaren algunes fustes per a venir al present regne per a socorrer-los e portar-los-se'n en allende; y essent arribats en lo present regne e trobant lo mal tractament que lo dit camp los havien fet e la gran matança y estrago que havien fet en ells, acordaren de portar-se'n en allende tots los que restaren vius en dit castell e baronia de Polop y serra de Bèrnia y llochs circumvehïns de aquella, com de fet los se'n portaren per força als dits Perot Payol, lo qual era de molt poca edat, com no tingué deu o onze anys, e Maria Payol, muller qui huy és de aquell, olim Nuca. ${ }^{63}$

De acuerdo con esta versión de los hechos, más detallada que el dubitativo testimonio inicial del acusado, Payol abandonó su tierra natal ocho años antes de lo que había asegurado, cuando era un chiquillo. ¿Y qué necesidad tenía de mentir? En su minucioso estudio del bautismo de los mudéjares por los agermanados, Rafael Benítez advierte de las discrepancias entre los cronistas sobre lo que sucedió en Polop.

62. Rafael Benítez SÁnchez-Blanco, «El verano del miedo: conflictividad social en la Valencia agermanada y el bautismo de los mudéjares, I52I", Estudis. Revista de Historia Moderna, 22 (1996), pp. 27-5I; Vicent J. VAllés Borràs, La Germanía, Alfons el Magnànim, Valencia, 2000, pp. 260-262.

63. ARV, Real Audiencia, Procesos, $2 .{ }^{a}$ parte, Letra P, $58,50 r-52 \mathrm{r}$. 
Mientras Miquel García y Rafael Martí de Viciana dan por sentado que la masacre se produjo una vez bautizados los musulmanes de la baronía, Guillem Ramon Catalá parece señalar que los mataron apenas prometieron bautizarse: «Foren contents los dits morets de obrir lo castell y batejar-se, y sobre la fe obriren lo castell. Y tantost, entraren los agermanats y mataren tots los morets que trobaren». ${ }^{64}$ Fijémonos en que el letrado Climent tampoco despeja la incógnita y emplea una frase ambigua: «e mataren alguns dels moros o moriscos que estaven en lo dit castell». Puestos a hacer suposiciones, es posible que Payol, deseando evitar que los jueces lo tomasen por moro y dudasen de su juramento y, por ende, de su sincero propósito de vivir como cristiano, prefiriese ocultarles que había emigrado a Berbería siendo un nińo por bautizar y fingiera haberlo hecho en I 529 como converso, pero compelido por los corsarios de Cachadiablo.

En ese caso, y ahondando en conjeturas, quizá la suya fuese una estrategia de defensa pactada con sus compañeros, al menos hasta que su procurador la reformuló. Como artífices de la fuga y cabezas de sus respectivas familias, Payol, Ballau y Zacarra eran bien conscientes de que para el tribunal la responsabilidad de los hechos juzgados recaía sobre sus hombros, y que por ello no solo les convenía, sino que era crucial presentar un frente unido. No habían puesto en peligro sus vidas huyendo de Cherchell ${ }^{65}$ para morir o acabar reducidos a esclavitud en Valencia. ${ }^{66}$ Que Nuca, mujer de Payol, del valle de Guadalest, Marien, esposa de Zacarra, natural de El Verger, y la viuda Erina, de Callosa

64. Rafael Benítez Sánchez-Blanco, «El verano del miedo», p. 45; Eulàlia DuRan, Cròniques de les Germanies, Edicions 3 i 4, Valencia, 1984, p. 243.

65. El maestro carpintero Alonso Cantalapiedra, que viajaba con cierta frecuencia a Argel y actuó también como traductor para la Audiencia, declararía en noviembre que sabía que en Cherchell y en Argel acostumbraban a confiscar los bienes de los fugitivos, y que a veces los ahorcaban. ARV, Real Audiencia, Procesos, 2. ${ }^{a}$ parte, Letra P, 58, 6ov-6Iv. Del mismo modo, varios de los fugados insisten en el temor que tenían de ser abordados por alguna fusta de moros antes de alcanzar la costa de Valencia.

66. En 1547 habían sido vendidas 29 cautivas alarbes para pagar a diversos oficiales regios los salarios que se les adeudaban. ARV, Maestre Racional, 8865, 37v, 38r y $39 \mathrm{r}$. 
d'En Sarrià, declarasen haber partido del reino durante las convulsiones de las Germanías no afectaba a la sustancia de sus pretensiones. ${ }^{67} \mathrm{La}$ clave para salir bien librados del juicio era insistir en el trasfondo coercitivo de su marcha al norte de África y en la incapacidad de todos ellos, hombres y mujeres, ya en razón de su edad, ya por su sexo, ya por miedo a los corsarios, para negarse a ser transportados. De ahí la apostilla, patentemente suasoria, de Miquel Jeroni Climent a su reconstrucción de la forma en que los moros de allende se habían llevado a Payol y Nuca en I52I: "com de fet los se'n portaren per força». Aunque, si se piensa bien, ¿era necesario después de la carnicería agermanada en Polop que coaccionasen a los supervivientes para que se apiñasen en las fustas?

Los archivos criminales, sostiene Arlette Farge, no dicen la verdad, pero hablan de la verdad; para dilucidarla, los historiadores se han de sumergir en aguas turbias, en las que se mezclan anhelos y temores de toda índole y grado, falsedades, omisiones, interpolaciones interesadas y múltiples factores contextuales y culturales. ${ }^{68} \mathrm{Si}$ hay una verdad incontrovertible que asoma a la superficie en este proceso penal de I55I es que, al contrario de lo habitual, los imputados no quieren pasarse allende, sino que retornan aquende. Como se agarran al clavo ardiente de que lo hacen para vivir como cristianos y los fiscales, obcecados en demostrar que la intención de los denunciados no era otra que ir a Argel, no les interrogan sobre sus condiciones de vida en Cherchell ni acerca de los bienes, parientes y ocupaciones que allí han quedado, solo podemos especular en torno a los motivos por los que optaron por dejar su tierra y se arriesgaron a abrirse camino en un nuevo entorno. Quizá las diferencias culturales y étnicas con la población autóctona terminasen erigiéndose en obstáculos insalvables para ellos. $\mathrm{O}$ tal vez, al igual que otros mudéjares o moriscos instalados en aquella parte del Magreb, se sintieran molestos o desubicados ante la vigilancia

67. ARV, Real Audiencia, Procesos, 2. ${ }^{a}$ parte, Letra P, $58,7 \mathrm{~V}-8 \mathrm{v}, \mathrm{I} 3 \mathrm{r}-\mathrm{I} 4 \mathrm{~V}$.

68. Arlette FARGE, La atracción del archivo, Alfons el Magnànim, IVEI, Valencia, 199I, pp. 26-28. Véase también Natalie Zemon Davis, Fiction in the Archives. Pardon tales and their tellers in Sixteenth Century France, Stanford University Press, Stanford (CA), 1987. 
más estrecha y la pérdida de influencia política y social que se derivaron del afianzamiento del sistema de poder instaurado por los Barbarroja en Argel. ${ }^{69}$ Algunos pasajes del testimonio de Caterina Cros apuntan en esa dirección, sobre todo los que atañen a la persecución de que fueron objeto ella y Obaydal por parte del capitán Morat y a la discreción y disimulo con que los tagarinos se auxiliaban unos a otros. ¿Acaso superadas las incomodidades de la etapa inicial de asentamiento les fue imposible a los reos materializar sus ulteriores esperanzas de mejora y decidieron por ello apostar su futuro a poniente? Recordemos las palabras de arrepentimiento de Zacarra ante la Audiencia: «si ell sabera sellavors lo que ara sab, no hu fera». ¿Era esa la causa?

Bien mirado, fuera cual fuese el factor determinante que los impulsó a volver al reino, parece obvio que no pudo ser su fervor de conversos. Basta reparar en que Payol, su esposa, la mujer de Zacarra y la viuda Erina no habían sido bautizados o acababan de recibir un apresurado bautismo cuando partieron a Berbería en I52I. Es improbable que Zacarra supiera los rudimentos de la fe en I532. Tampoco Abrahim Payol, hijo de Alí, ni su esposa y hermanastra Fátima, nacidos en Cherchell, podían conocer la doctrina cristiana. Quizá Ballau y su esposa, que salieron en $\mathrm{I} 538$, estuviesen familiarizados con alguna práctica devocional, pero es harto dudoso, por cuanto en aquel ańo ni siquiera se había formalizado un plan de aculturación y las campañas de evangelización se harían esperar hasta la década siguiente. ${ }^{70}$ Por fortuna para los

69. Mikel de Epalza, «Papel político de los moriscos en el nacimiento de la Argelia moderna en tiempos de Carlos V», en M. J. Rubiera Mata, coord., Carlos V, los moriscos y el Islam, Sociedad Estatal para la conmemoración de los centenarios de Felipe II y Carlos V, Madrid, 200I, pp. 20I-232; Luis F. Bernabé Pons, «Vivir y negociar. Los moriscos entre dos mundos», en A. I. López-Salazar y F. J. Moreno Díaz del Campo, coords., La monarquía hispánica y las minorías. Élites, poder e instituciones, Sílex, Madrid, 2019, pp. I23-I47.

70. Rafael Benítez Sánchez-Blanco, «Antonio Ramírez de Haro y los moriscos valencianos», en Les morisques et leur temps, CNRS, París, 1983, pp. I27-I57; Heroicas decisiones. La Monarquía Católica y los moriscos valencianos, Alfons el Magnànim, Valencia, 200I, pp. I4O-I48; Bernard VINCENT, «La evangelización de los moriscos: las misiones de Bartolomé de los Ángeles», El río morisco, pp. I45-I54. 
acusados, estas contradicciones, que habrían sido detectadas con facilidad y escrutadas a fondo por los inquisidores, ${ }^{71}$ no llamaron la atención de los fiscales de la Audiencia, más preocupados por averiguar cuánta comida traían en la barca (para probar la falsedad de que su travesía hubiera sido planificada), y en sus contactos con presuntos candidatos a pasarse a África. ${ }^{72}$

Pero volvamos a la cuestión que aquí nos ocupa: la naturaleza coercitiva de la emigración a Berbería de los moriscos procesados. Como ocurre a menudo en los pleitos criminales, más fidedignas y esclarecedoras que las voces de los reos son las de los testigos llamados a declarar (en este caso concreto por la defensa, más numerosos que los convocados por la fiscalía). En relación con la partida de Martí Zacarra en I532, Joan Jagel, morisco de Potries, señala que por entonces vivía con su hermano en Tavernes de la Valldigna. Cuando la armada de Salah Rais vino para embarcar a los nuevos convertidos del valle, vio que algunos, "per no anar-se'n, fugien a la muntanya; e a tots los que no pogueren fugir los feren passar davant y enbarcar per força». ${ }^{73}$ Uno de los que sí consiguió escapar fue Sebastià Maçut, nacido en Villalonga, pero en aquellas fechas residente en Tavernes, como el mencionado Jagel, que recuerda a Zacarra y «su amo» — posiblemente el tío de Martí-, siendo conminados a marchar. ${ }^{74}$ Incluso el arráez Omat Arpet, preso en Valencia a la espera de ejecución, ${ }^{75}$ admite que la madre y el hermano de Zacarra, con quienes tenía trato por ser natural de Oliva, le habían dicho que los soldados de Salah Rais se lo llevaron por la fuerza. ${ }^{76}$ Por

7I. Benítez ha datado precisamente en I55I, con la visita del inquisidor Gregorio Miranda, el inicio de la lenta recuperación de la actividad inquisitorial en el reino de Valencia. Benítez Sánchez-Blanco, Heroicas decisiones, p. I68.

72. ARV, Real Audiencia, Procesos, 2. ${ }^{a}$ parte, Letra P, 58: escrito de acusación de los fiscales Francesc Joan Cardona y Pere Joan Alreus, 20r-23r.

73. Ibidem, 69v-7or.

74. Ibidem, 68r-v.

75. Prestó declaración el I de diciembre de I55I. Murió en la horca y fue descuartizado un mes después. Cfr. Pérez García y Catalá Sanz, "La pena capital», p. 78.

76. ARV, Real Audiencia, Procesos, 2. ${ }^{a}$ parte, Letra P, 58, 66v-67r. 
su parte, aunque no conoce al acusado - y esto hace aún más relevante su testimonio-, el ciudadano Bernat Cerveró, que en I 532 estaba al servicio del duque de Gandía, afirma que cuando fue a visitar a don Juan de Borja después del trance se tropezó con moriscos del valle de Alfandec que le confesaron que muchos habían sido obligados a dejar sus casas, "y que si ells eren estats era perquè havien fugit a la muntanya per no anar ab ses mullers e fills y ab lo que se'n havien pogut portar; y que ells no sabien res en la venguda de los moros de allende». ${ }^{77}$ Otro testigo que luchó a las órdenes del duque contra las tropas incursoras, ${ }^{78}$ Martí de Mur, ${ }^{79}$ subraya que muchas personas le contaron que, en el camino a Cullera, los corsarios daban de bastonazos a los nuevos convertidos que no querían embarcarse. ${ }^{80}$

No son menos elocuentes los testimonios sobre la salida de Suleimén Ballau y su esposa Nesma durante la correría de Axe Baxá en I538. El mencionado Arpet relata que Queney, hermano de Ballau, le contó apesadumbrado en el mercado de Gandía que los moros de la mar se lo habían llevado contra su voluntad. ${ }^{81}$ Otro patrón encarcelado en Valencia, Amar, nacido en Orán pero con base en Cherchell, asegura que vio llorar con amargura a Ballau y su mujer cuando arribaron a esta ciudad, desolados porque «lo dit Agí Baxà los havia tots despullats e portats per força». ${ }^{82}$ Joan Tenala, morisco del valle de Xaló, confirma que los corsarios golpeaban a los nuevos convertidos reacios a seguirlos. ${ }^{83} \mathrm{Un}$ avispado convecino, Joan Dolxa, encontró, no obstante, el modo de huir de ellos: empujado a unirse a la fila junto con Ballau, Nesma y otros

77. Ibidem, 64r.

78. Sobre el combate en l'Estany de Cullera, véase Pardo Molero, La guerra $i$ els cavallers, pp. 94-IOI.

79. Seguramente se trate del mismo Martí de Mur elegido jurado de la villa de Gandía en I52I que tuvo un destacado papel en el ejército ducal contra los agermanados. Francesc Pons Fuster, La Germania a Gandia i el duc Joan de Borja, CEIC Alfons el Vell, Gandía, 2008, p. 134.

80. ARV, Real Audiencia, Procesos, 2. ${ }^{a}$ parte, Letra P, 58, 63r-v.

8I. Ibidem, 67v.

82. Ibidem, $72 \mathrm{r}-\mathrm{v}$.

83. Ibidem, 73 r. 
lugareños, acertó a darles esquinazo en el trayecto hasta las naves ancladas en Calpe. ${ }^{84}$

Por último, el doncel Cristòfol Ballester revela algo muy interesante, que, como el caso de Bertomeu Ferri y sus tripulantes moriscos en I547, pone de manifiesto que la solidaridad interétnica podía surgir a pesar de las tensiones crecientes entre cristianos viejos y nuevos. Tan pronto como los de Xaló recibieron aviso de que más de veinte fustas rondaban las Peñas del Albir, un morisco amigo de la familia fue a advertir a su padre de que, aunque no se tenía certeza de que las naves fuesen musulmanas, tomase la precaución de hacer subir a su mujer y sus hijos a la torre de su casa. Un par de horas después, cientos de argelinos se agolparon a las puertas de esta y secuestraron a su padre y una criada. Solo al día siguiente se atrevió el joven Ballester a salir de su refugio para evaluar los dańos; preguntando a algunos moriscos que se habían quedado en el valle se enteró de que Ballau y su esposa figuraban entre quienes habían sido embarcados por la fuerza. ${ }^{85}$

De lo dicho se infiere que, como Çabdonet de Callosa en I549-y parte de sus paisanos en 1584-, fueron más de los que cabe suponer los nuevos convertidos que, queriendo permanecer en sus tierras, tuvieron que cruzar a la otra orilla violentados por sus correligionarios de ultramar. Cosa distinta es que, al igual que los protagonistas del proceso de I55I, tuvieran los medios y la oportunidad de retornar a la península cuando se hartaron de una realidad en la que no encajaban. Otros, sin embargo, se rebelaron contra ese destino, como Sebastià Maçut, Joan Dolxa y los demás moriscos de los valles de Alfandec y Xaló que se encaramaron a las montańas para evitar la mudanza.

Un último testimonio extraído de la misma causa judicial ilustra, para concluir, la diversidad de criterios que, en encrucijadas como aquellas, podían llevar a obrar en un sentido u otro. Cuenta Miquel Bellvís, morisco de Oliva que en I52I había tenido que trasladarse a Polop a raíz de un enfrentamiento entre bandos en el que se había in-

84. Ibidem, $73 \mathrm{v}$.

85. Ibidem, 65v-66v. 
volucrado, que cuando los agermanados perpetraron la masacre en aquella baronía:

moltes dones y alguns hòmens, entre les quals és la dita Herina [de Callosa], se enbarcaren de por, perquè los agermanats no.ls matassen, ab les fustes y galeres que estaven en Bèrnia, ell, dit testimoni, també se enbarcà en les dites fustes per por que no.l matassen.

Bellvís daba por supuesto que sus hermanos y primos también se habían subido a las naves y que podría reunirse con ellos en Argel, pero en el último momento supo que, pese a la brutalidad exhibida por los agermanados al bautizarlos ${ }^{86}$ habían optado por quedarse en sus casas. Entonces, sobreponiéndose al pánico, decidió poner pie en tierra y regresar a Oliva. ${ }^{87}$ Ello sugiere que los mismos vínculos de fraternidad y lealtad que lo habían llevado a su destierro temporal en Polop le empujaron también a bajarse de la fusta corsaria, al no concebir la vida separado de sus familiares y, en definitiva, de su patria.

86. Benítez Sánchez-Blanco, «El verano del miedo», p. 29.

87. ARV, Real Audiencia, Procesos, 2. ${ }^{a}$ parte, Letra P, 58, 75 r-v. 